\begin{tabular}{|l|l|l|l|l|}
\hline \multirow{2}{*}{ apt 1 DLPS } & elps201300052 & Dispatch: June 21, 2013 & CE: \\
\cline { 2 - 5 } & Journal & MSP No. & No. of pages: 8 & PE: XXXXX \\
\hline
\end{tabular}

Márta Kerékgyártó ${ }^{1}$

Anikó Fekete ${ }^{2}$

Zoltán Szurmai ${ }^{3}$

János Kerékgyártó ${ }^{3}$

László Takács ${ }^{4,5}$

István Kurucz ${ }^{5 *}$

András Guttman ${ }^{1,6 *}$

${ }^{1}$ Horváth Laboratory of

Bioseparation Sciences,

University of Debrecen,

Debrecen, Hungary

${ }^{2}$ Department of Organic

Chemistry, University of

Debrecen, Debrecen, Hungary

${ }^{3}$ Faculty of Sciences and

Technology, University of

Debrecen, Debrecen, Hungary

${ }^{4}$ Antibody Proteomics

Laboratory of the Department of

Human Genetics Medical and

Health Science, University of

Debrecen, Debrecen, Hungary

${ }^{5}$ BioSystems International Kft,

Debrecen, Hungary

${ }^{6}$ MTA-PE Translational Glycomics

Research Group. University of

Q1 Pannonia, Veszprem, Hungary

Received January 30, 2013

Revised April 11, 2013

Accepted April 11, 2013
Research Article

\section{Neoglycoproteins as carbohydrate antigens: Synthesis, analysis, and polyclonal antibody response}

\begin{abstract}
The analysis and polyclonal antibody response for newly synthesized maltose-BSA conjugate neoglycoproteins is described. In this first proof of concept study, a simple carbohydrate antigen, maltose, was linked to BSA by reductive amination. An aglycone spacer was utilized to conserve the intact annular maltose structure and to promote the accessibility of the carbohydrate immunogen hapten during immunization. The neoglycoproteins were investigated by CGE and the number of conjugated maltose residues was determined by MALDI-TOF MS. The neoglycoproteins were then evaluated by immunization of BALB/c mice and the polyclonal antibody response was tested by ELISA as evidence for the presence of sugar-containing epitope-specific antibodies. Selective antibody binding was demonstrated to the synthesized neoglycoproteins with different (low and high) glycosylation degrees suggesting the possible use of this approach to generate antibodies. Moreover, the polyclonal antibody response was not inhibited by maltose or other simple carbohydrates to confirm presence of the neoglycoprotein-specific antibodies.
\end{abstract}

\section{Keywords:}

Carbohydrate antigen / Carbohydrate-specific antibody / ELISA / Neoglycoprotein

DOI 10.1002/elps.201300052

Additional supporting information may be found in the online version of this article at the publisher's web-site

\section{Introduction}

Glycobiology and the study of glycoproteins became increasingly important in the past few years [1-3]. Carbohydrate moieties are predominant surface components of cells such as erythrocytes, immune cells, microorganisms, etc., and proved to be essential partners in many biological recognition processes [4]. Interactions of proteins or lipids with glycans, namely complex oligosaccharides that are attached to proteins or lipids, play a significant role in the antigen and/or pathogen recognition machinery [5], malignant transformation [6], neurological disorders [7], etc. Naturally occurring and adaptive antiglycan antibody development against carbohydrate antigens is of increasing importance since glycosylation is recognized as a significant player in biomarker research and discovery [8]. The anticarbohydrate antibodies

Q2 Correspondence: Professor András Guttman, Horváth Laboratory of Bioseparation Sciences, Medical and Health Science, University of Debrecen, Debrecen, Hungary

E-mail: guttman.andras@hlbs.org

Fax: $+36-52-414-717 \not \varnothing 5539$

Q3 Abbreviations: mCGE, Aplticapillary gel electrophoresis; PGA, printed glycan array can be useful as diagnostic markers for detecting carbohydrate antigens in various diseases [9]. Moreover, anticarbohydrate antibodies hindering or promoting therapeutic potential may occur as neoglycoprotein-based antibacterial vaccines or neoglycoprotein-based antitumor vaccines for cancer [10]. The advent of anticarbohydrate antibodies such as antilaminaribioside and antichitobioside holds the promise to detect glycans, which are characteristic for various diseases $[1,4]$.

Neoglycoproteins as sugar-specific antigens were first used as vaccines as early as in 1931 by Avery and Goebel [11], and since then they have been utilized in a wide variety of applications, such as diagnostic markers [12] as immune response triggers antitumor-associated carbohydrate antigens [13]. With their possible oncogenic role recognized, naturally occurring sugar-specific antibodies seem to play an important part in antitumor surveillance, probably by binding to the repetitive motif of carbohydrate epitopes [14]. Meanwhile, differential glycosylation is a hallmark of tumor-associated carbohydrate antigens [15]. Cancer-associated carbohydrates are mostly located on the surface of cancer cells and represent potential targets for new diagnostic assays and therapeutic treatments [16]. Antiglycan autoantibodies in their possible

\footnotetext{
*These authors contributed equally to this work.
} 
malignancy-defining role have been first described in breast cancer and Hodgkin's lymphoma [17]. The synthesis of neoglycoproteins primarily involves random or defined coupling sites on the surface of the carrier protein, which is covalently modified with glycans via their reducing end or functionalized glycan bearing spacer arms $[10,18,19]$. Complex carbohydrates and neoglycoproteins are routinely used for a variety of biological assays. Currently, the most frequently used glycanbased assays are printed glycan array (PGA), multiplex flow cytometric suspension assay, and ELISA. Although, the conventional ELISA technique provides assessment of a limited number of glycan-protein interactions, it is still the most widely used method for this type of application [20,21]. PGA is one of the newest high-throughput microarray techniques that enable studying biomolecular interactions $[22,23]$. Both in ELISA and PGA, the interrogating sugar structures are located on a flat surface. In PGA, sugars are covalently attached to the surface of a glass slide in a monovalent form as $\omega$-alkyl glycosides (Glyc-sp- $\mathrm{NH}_{2}$ ), whereas in ELISA they are physically absorbed to polystyrene in multivalent form, as conjugates with a polyacrylamide or albumin carrier [24]. The existence of naturally occurring antiglycan autoantibodies $[17,23]$ suggests that although not widely anticipated, elicitation of specific antibodies to defined glycans may be possible. An obvious application of glycan-specific polyclonal or monoclonal antibodies is biomarker discovery via comprehensive and specific detection of disease-specific glycosylation changes. In the future, these sugar-specific antibodies may provide sensitive and specific complementary assays to the currently used PGA and ELISA methods.

CGE in the presence of SDS is a widely used method for the separation and analysis of glycoproteins, which offers high resolving power and rapid separation times [25-27]. Moreover, CGE represents many advantages over classical SDS-PAGE including automation, on-column direct UV, LIF, or LED-IF detection options and accurate quantification of biopolymers [28]. Another alternative is microfluidic chip based electrophoresis methods that provide significantly shorter analysis times, but frequently suffers from limited resolution due to the short separation channel length. Multicapillary gel electrophoresis (mCGE) with LED-IF, on the other hand, is reportedly applicable to rapid and large-scale analysis of biomolecules [29]. Another important tool for structural analysis of carbohydrates is MS that offers precise molecular mass data, analytical versatility, and good sensitivity [30]. MALDI was successfully developed as a soft ionization method for biopolymer analysis less than two decades ago. This technique is capable of direct mass measurement of high molecular weight compounds such as synthetic polymers, proteins, oligonucleotides, or complex carbohydrates [31].

In this paper, we report on the synthesis and $\mathrm{CE}$ (mCE) as well as MALDI-TOF MS analysis of neoglycoproteins (maltose-conjugated BSA) and results are presented on their ability to elicit specific immune response. BSA was chosen as a carrier since in its natural form it voids glycosylation. Neoglycoproteins were synthesized under controlled condi- tions with different numbers of oligomeric/ dimeric maltose molecules (between 32 and 66 units $/ \mathrm{mol}$ ) conjugated to the lysine $\varepsilon$-amino residues of BSA. The polyclonal antibody response was evaluated in mice. Adaptation of this approach as good working model was planned for conjugation of complex disease specific sugar structures to carriers in order to generate printed antiglycan microarrays.

\section{Experimental methods}

\subsection{General procedures}

All reagents and chemicals for the synthesis of neoglycoproteins and the general reagents for CE, MALDI-TOF MS, and ELISA tests were purchased from Sigma-Aldrich (St. Louis, MO, USA). TLC was performed on Kieselgel $60 \mathrm{~F}_{254}$ precoated aluminum plates (Merck, Darmstadt, Germany). Compounds were visualized by treating the plates with $10 \%$ $\mathrm{H}_{2} \mathrm{SO}_{4}$ and heating to $140^{\circ} \mathrm{C}$. Column chromatography was performed with Kieselgel 60 (Merck, 0.063-0.2 mm) with solvents specified under the relevant sections. After extraction, all organic phases were concentrated in a rotary vacuum evaporator (Büchi Rotavapor R-114, Flawil, Switzerland). The uncorrected melting points were determined by a Kofler apparatus (Dresden, Germany). NMR spectra were recorded on a Bruker (Bremen, Germany) DRX-360 instrument $\left({ }^{1} \mathrm{H}\right.$ $360.13 \mathrm{MHz},{ }^{13} \mathrm{C} 90.56 \mathrm{MHz}$ ) at room temperature in $\mathrm{CDCl}_{3}$ solvent, using $\mathrm{Me}_{4} \mathrm{Si}$ as internal standard (see Supporting Information).

\subsection{Synthesis of neoglycoproteins}

Acetylation step: All the OH groups of maltose were acetylated by acetic anhydride and sodium acetate to yield crystalline compound, 2,3,4,6-tetra-O-acetyl- $\alpha$-D-glucopyranosyl-( $1 \rightarrow 4)$ 1,2,3,6-tetra-O-acetyl- $\beta$-D-glucopyranose. Deprotection step: After that the anomeric $\mathrm{OH}$ group of maltose octaacetate was deprotected by hydrazine-acetate and then 2,3,4,6-tetra-O-acetyl- $\alpha$-D-glucopyranosyl-( $1 \rightarrow 4)$-2,3,6tri-O-acetyl- $\beta$-D-glucopyranose compound was converted into the corresponding trichloroacetimidate donor.

Spacer addition step: The trichloroacetimidate donor was reacted with the 7-(1,3-dioxan-2-yl)-heptan-1-ol spacer. Conjugation step: The synthesized product was deprotected and then the functionalized maltose was conjugated into BSA by reductive amination to form neoglycoprotein. See details in Supporting Information.

Please note that a formyl-heptyl spacer was used at the reducing end of the carbohydrate hapten $[32,33]$ to minimize the risk of introducing a stronger immunogen close to the sugar residue, i.e. this spacer contains no functional groups in the vicinity of the carbohydrate. The coupling reactions were performed for different rations hapten-spacer/BSA, so different neoglycoproteins were obtained (BSA-32-maltose, BSA-50-maltose, BSA-59-maltose, and BSA-66-maltose), respectively. See details in Supporting Information. 


\subsection{Fluorophore labeling and CGE analysis of neoglycoproteins}

For neoglycoprotein labeling, the fluorescent reagent Chromeo P503 (Active Motif; Rixensart, Belgium) was dissolved in methanol in a final concentration of $1 \mathrm{mg} / \mathrm{mL}$ and the stock solution was kept at $4{ }^{\circ} \mathrm{C}$. The synthesized glycoconjugates were diluted in MilliQ-grade water (Millipore, Billerica, MA, USA) in a final concentration of $2 \mathrm{mg} / \mathrm{mL}$. A total of $5 \mu \mathrm{L}$ of each sample was transferred to a $200-\mu \mathrm{L}$ PCR tube for the SDS-mCGE analysis followed by the addition of $2 \mu \mathrm{L}$ of $0.5 \mathrm{M}$ DTT reducing agent, $0.5 \mu \mathrm{L}$ of $1 \mathrm{mg} / \mathrm{mL}$ dye stock solution, $2.5 \mu \mathrm{L}$ of $10 \% \mathrm{SDS}$, and $25 \mu \mathrm{L}$ of $25 \mathrm{mM}$ $\mathrm{NaHCO}_{3}$ buffer (final concentration: $17.86 \mathrm{mM}$; pH 9.20) to a total volume of $35 \mu \mathrm{L}$ and incubated at $90^{\circ} \mathrm{C}$ for $30 \mathrm{~min}$. The samples were then allowed to cool to ambient temperature and centrifuged at $3000 \times \mathrm{g}$ for $30 \mathrm{~s}$ (Centrifuge 5424, Eppendorf, Hamburg, Germany) prior to the mCGE analysis. TRIS-borate $(60 \mathrm{mM}$ ) containing $0.1 \% \mathrm{SDS}$ (pH 8.45) buffer was used as BGE in all electrophoretic analysis. The sample buffer contained $25 \mathrm{mM} \mathrm{NaHCO} 3$ and the $\mathrm{pH}$ was adjusted to 9.2 by the addition of $0.1 \mathrm{M} \mathrm{NaOH}$. All buffers and reagents were filtered through $0.22 \mu \mathrm{m}$ pore size Acrodisc (Millipore) syringe filters and degassed before use.

All separations were performed in a P/ACE MDQ CE system (Beckman Coulter, Brea, CA, USA). The unit was equipped with a 488-nm Ar-ion laser having a strong 514-nm line and the emission signal was collected through a $600-\mathrm{nm}$ long pass filter. The separation capillary $(10 \mathrm{~cm}$ effective length and $30 \mathrm{~cm}$ total length, $75 \mu \mathrm{m}$ id) was first rinsed with water, then $0.1 \mathrm{M} \mathrm{HCl}$, and flushed again with water before the SDS-MW gel buffer (Beckman Coulter) was transferred into the capillary. Prior to each injection, the sieving matrix was replaced in the column. The sample injection process was preceded by the introduction of an HPLC-grade water plug $(12.5 \mathrm{kV}$ for $5 \mathrm{~s})$. The samples were introduced electrokinetically at the short side of the capillary $(10 \mathrm{~cm})$ from a 96-well plate $(25 \mathrm{kV}$ for $10 \mathrm{~s})$. All separations were carried out at $25^{\circ} \mathrm{C}$ by applying $500 \mathrm{~V} / \mathrm{cm}$ electric field strength. The Karat 32 version 7.0 software package (Beckman Coulter) was used for data acquisition and analysis.

\subsection{Analysis of neoglycoproteins by MALDI-TOF MS}

MALDI-TOF MS based molecular mass assessment of the synthesized neoglycoproteins was carried out in positive reflectron mode using a BIFLEX III mass spectrometer (Bruker) with delayed-ion extraction. Spectra from multiple (>100) laser shots $\left(\mathrm{N}_{2}\right.$ laser, $\left.337 \mathrm{~nm}\right)$ using $19 \mathrm{kV}$ accelerating and $20 \mathrm{kV}$ reflectron voltage were summarized. External calibration was applied using BSA (6-8 mg/mL in $0.1 \%$ TFA). TA solution was prepared by dissolving $0.1 \%$ TFA in a mixture

Q4 of 2:1 ACN-water. A total of $10 \mu \mathrm{L}$ of sample, $25 \mu \mathrm{L}$ matrix (3,5-dimethoxy-4-hydroxycinnamic acid), and $15 \mu \mathrm{L}$ TA solution were mixed and $0.5 \mu \mathrm{L}$ was applied to the target plate and allowed to dry at room temperature before analysis.

\subsection{Immunization with neoglycoproteins}

For each immunization step (BALB/c mouse $\circ$, Charles River Hungary, Isaszeg, Hungary), both the lowest (32 units/mol) and highest ( 66 units/mol) amount of sugar-incorporated synthetic neoglycan immunogens $(50 \mu \mathrm{g} / \mathrm{mL}$ in phosphate buffered saline, $\mathrm{pH}$ 7.4) were mixed with equal volume of Freund's complete adjuvant and incomplete Freund's adjuvant for the first and consecutive immunization injections, respectively. The mixture was injected subcutaneously into the hindfeet of the mice three times in 2-week intervals. Seven to ten days after the third injection, blood was taken from the eye corners of the mice. The serum was separated from the red blood cells and tested by ELISA.

\subsection{Analysis of carbohydrate-specific antibodies with ELISA}

Immunoassay plates (Corning 96-well plates, half-area clear polystyrene, high-binding, nonsterile, Sigma-Aldrich) were coated with synthetic neoglycoprotein as immunogens, $30 \mu \mathrm{L}$ per well in the coating buffer of $14.7 \mathrm{mM} \mathrm{Na}_{2} \mathrm{CO}_{3}, 34.9 \mathrm{mM}$ $\mathrm{NaHCO}_{3}, \mathrm{pH} 9.6$, and incubated at $37^{\circ} \mathrm{C}$ for $1 \mathrm{~h}$. A total of $10 \mu \mathrm{g} / \mathrm{mL}$ and a twofold serial dilution from 1.25 to $0.08 \mu \mathrm{g} / \mathrm{mL}$ of immunogen coatings were used to detect the polyclonal antibody response, and $0.2 \mu \mathrm{g} / \mathrm{mL}$ BSA and synthetic neoglycoprotein as immunogen coatings were prepared for the experiments, which were done in the presence of inhibitors. The plates were washed twice with PBS-

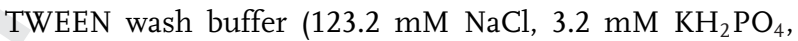
$10.5 \mathrm{mM} \mathrm{Na}_{2} \mathrm{HPO}_{4}, 0.05 \mathrm{v} / \mathrm{v} \%$ Tween-20, pH 7.2), the remaining protein-binding sites were blocked by the addition of $60 \mu \mathrm{L}$ PVP-blocking buffer $(376.5 \mathrm{mM} \mathrm{NaCl}, 0.5 \mathrm{~m} / \mathrm{v} \%$ polyvinyl-pyrrolidone in the PBS-TWEEN buffer) and incubated at $37^{\circ} \mathrm{C}$ for $30 \mathrm{~min}$. Then, the plates were washed twice with wash buffer and $30 \mu \mathrm{L}$ of appropriately diluted immune sera was added to each well followed by incubation at $37^{\circ} \mathrm{C}$ for $1 \mathrm{~h}$. Serum dilutions of 1000-128 $000 \times$ were used to check the polyclonal antibody response. Then, the plates were washed four times with the wash buffer. This was followed by washing the plates four times with wash buffer before $30 \mu \mathrm{L}$ of appropriately (8000-fold) diluted horseradish peroxidase (HRP-labeled) conjugated secondary antibody (goatanti-mouse IgG, Southern Biotechnology, Birmingham, AL, USA) was added to each well and incubated at $37^{\circ} \mathrm{C}$ for 30 min. To measure the bound antibody, $30 \mu \mathrm{L}$ of $3,3^{\prime}, 5,5^{\prime}$ tetramethylbenzidine substrate solution was added to each well. This solution consisted of 3,3',5,5'-tetramethylbenzidine tablet dissolved in the mixture of $1 \mathrm{~mL}$ DMSO and $9 \mathrm{~mL}$ citrate-phosphate buffer $\left(52.0 \mathrm{mM} \mathrm{Na} \mathrm{HPO}_{4}, 25.5 \mathrm{mM}\right.$ citric acid, $\mathrm{pH} 5.0$ ). A total of $2 \mu \mathrm{L}$ of fresh $30 \%$ hydrogen peroxide was added per $10 \mathrm{~mL}$ of substrate buffer solution immediately prior to use. The estimated incubation times for the enzyme-substrate reaction ranged from 10 to $15 \mathrm{~min}$, after which $30 \mu \mathrm{L}$ stop solution $\left(4 \mathrm{M} \mathrm{H}_{2} \mathrm{SO}_{4}\right)$ was added to the reaction and the plates were interrogated at $450 \mathrm{~nm}$ in 
a Multiscan Ascant reader (Thermo Scientific, Hudson, NH, USA).

In the inhibition studies, $0.1-1.6 \mu \mathrm{g} / \mathrm{mL}$ BSA, neoglycoproteins, and $2.00-0.06 \mathrm{mg} / \mathrm{mL}$ maltose, glucose, isomaltose, lactose, galactose, and maltodextrin were used to inhibit the binding of specific antibodies from the suitably diluted (2000-fold) plasma preparations. 4000-fold dilution of sera was prepared without inhibitors as control. After coating and blocking, the serum was mixed with an equal volume of the inhibitor. The mixture was placed on the well and incubated for $1 \mathrm{~h}$ at $37^{\circ} \mathrm{C}$. This was followed by washing the plates four times with wash buffer before $30 \mu \mathrm{L}$ of appropriately (8000-fold) diluted horseradish peroxidase (HRP labeled) conjugated secondary antibody (goat-anti-mouse IgG, Southern Biotechnology) was added to each well and incubated at $37^{\circ} \mathrm{C}$ for $30 \mathrm{~min}$. Then the plates were washed four times with the wash buffer. Antibody binding was measured as described above.

\section{Results and discussion}

\subsection{Neoglycoprotein synthesis}

The synthesis of carbohydrate hapten for the generation of the neoglycan immunogen started with reacting maltose with acetic anhydride to form the maltose octaacetate, followed by the removal of the anomeric acetyl group to yield the hemiacetal anomers. The anomeric configuration was verified by NMR (see Supporting Information). The resulted hemi-acetal was transformed to a trichloroacetimidate donor and then reacted with the aglycone spacer of 7-(1,3-dioxan-2-yl)-heptan-1ol to form a protected maltose with the formyl-heptyl spacer. Before the conjugation step, the protecting acetal group and acetyl groups were removed and the resulting aldehyde was linked to the lysine $\varepsilon$-amino groups of BSA to form the Schiff base, which was consequently reduced with $\mathrm{NaCNBH}_{3}$ to obtain a stable neoglycoprotein that served as synthetic carbohydrate hapten of the immunogen.

\subsection{CGE and MALDI-TOF MS analysis of neoglycoproteins}

The reaction resulted in different number of sugar residues on the BSA molecules. The reaction products were first analyzed by capillary SDS gel electrophoresis for purity and homogeneity. Figure 1 depicts the capillary SDS gel electrophoresis traces showing the unconjugated dye (first peak at $10 \mathrm{~min}$ ) and the generated conjugates (second peak), having 32, 50, 59, and 66 units $/ \mathrm{mol}$ maltose units as determined by MALDI-TOF MS (see below). One can observe the longer migration times and suppressed signal intensity of the conjugates with increasing sugar unit content. The former is due to the effect of the larger molecular mass of the conjugates with the attached maltose residues and the concomitantly suppressed SDS binding to these hydrophilic patches, both
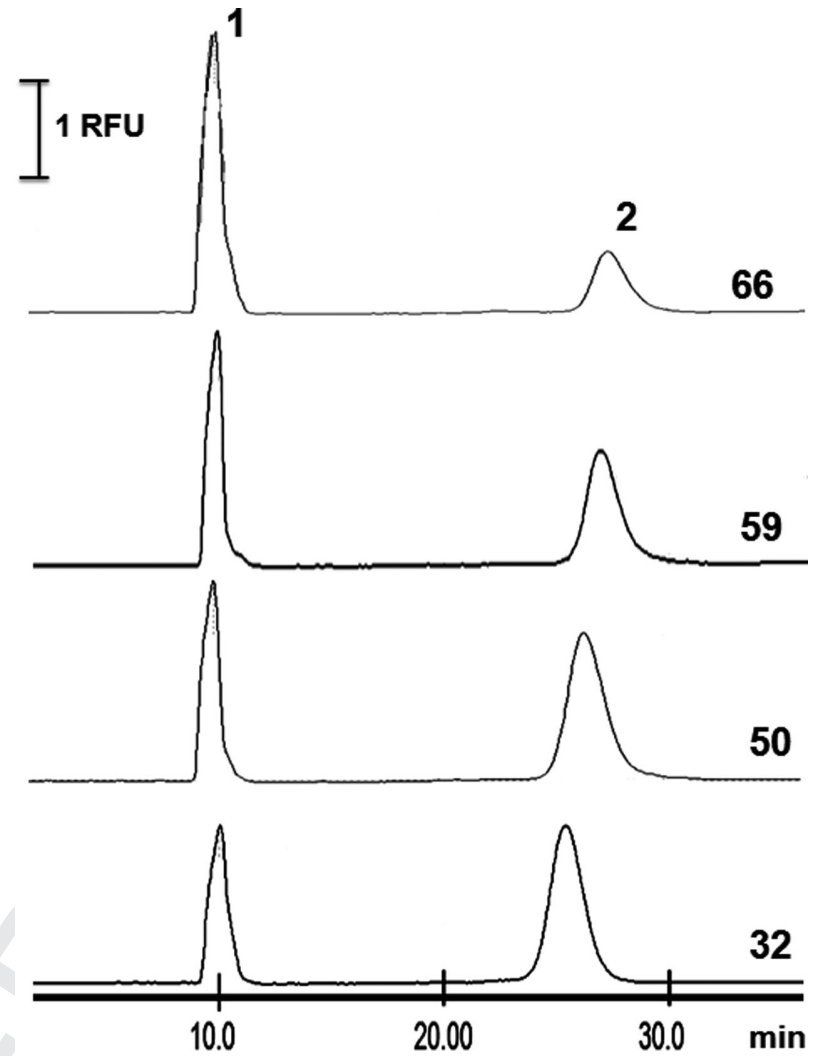

Figure 1. Typical CGE analysis of covalently fluorophore tagged and reduced glycoconjugate samples. Peaks: (1) remaining labeling dye, (2) maltose-conjugated BSA. Separation conditions: bare fused silica capillary (effective length: $10 \mathrm{~cm}$; total length: $30 \mathrm{~cm}$, $75 \mu \mathrm{m}$ id); BGE: SDS-MW gel buffer (Beckman Coulter); applied electric field strength: $500 \mathrm{~V} / \mathrm{cm}$; electrokinetic injection: $25 \mathrm{kV}$ for $10 \mathrm{~s}$; separation temperature: $25^{\circ} \mathrm{C}$.

causing migration time increase. The decreasing signal intensity of the conjugate (and the increasing signal intensity of the unconjugated free dye) with the increasing maltose content is due to the reduced number of available conjugation sites for the fluorescent dye, i.e. remaining free amino residues on BSA.

The exact number of conjugated maltose units was determined by MALDI-TOF MS as shown in Table 1. Please note that by increasing the molar ratio of the disaccharides to BSA, the incorporation level of sugars increased from 32 to 66 units. Since BSA only contains 60 free amino groups, as a first approximation we considered that in some instances tertiary amines were formed during the reductive amination step acquiring two sugar structures [34], consequently increasing the number of conjugated glycans beyond 60 .

\subsection{Polyclonal antibody response elicited by neoglycoproteins}

Using neoglycoproteins with low and high sugar incorporation levels (32 and 66 maltose units per BSA) as immunogens, 
Table 1. Analysis of the number of conjugated sugar residues in the synthesized antigens by MALDI-TOF MS and parameters of the conjugation step

\begin{tabular}{|c|c|c|c|c|}
\hline & \multicolumn{3}{|l|}{ Neoglycoproteins } & \multirow{2}{*}{ BSA-66-maltose } \\
\hline & BSA-32-maltose & BSA-50-maltose & BSA-59-maltose & \\
\hline Maltose containing spacer (mM) & 0.025 & 0.05 & 0.075 & 0.15 \\
\hline Acetic acid (mL) & 1.18 & 2.36 & 3.54 & 7 \\
\hline Water (mL) & 0.3 & 0.6 & 0.9 & 1.8 \\
\hline Phosphate buffer (mL) & 2 & 2 & 2 & 2 \\
\hline BSA (nM) & 250 & 250 & 250 & 250 \\
\hline $\mathrm{NaCNBH}_{3}(\mathrm{mM})$ & 0.050 & 0.1 & 0.15 & 0.3 \\
\hline Amount of antigens (mg) & 4.5 & 19.2 & 9.9 & 18.6 \\
\hline MALDI-TOF MS (Da) ${ }^{\text {a) }}$ & 80851.1 & 88854.5 & 93171.6 & 96258.5 \\
\hline Carbohydrate units & 32 & 50 & 59 & 66 \\
\hline
\end{tabular}

a) Sugar-spacer $\left(\mathrm{C}_{20} \mathrm{H}_{35} \mathrm{O}_{11}\right): 451 \mathrm{Da}$; BSA: $66401 \mathrm{Da}$; Calculation: $(80851-66$ 401)/451 = 32 units.

A

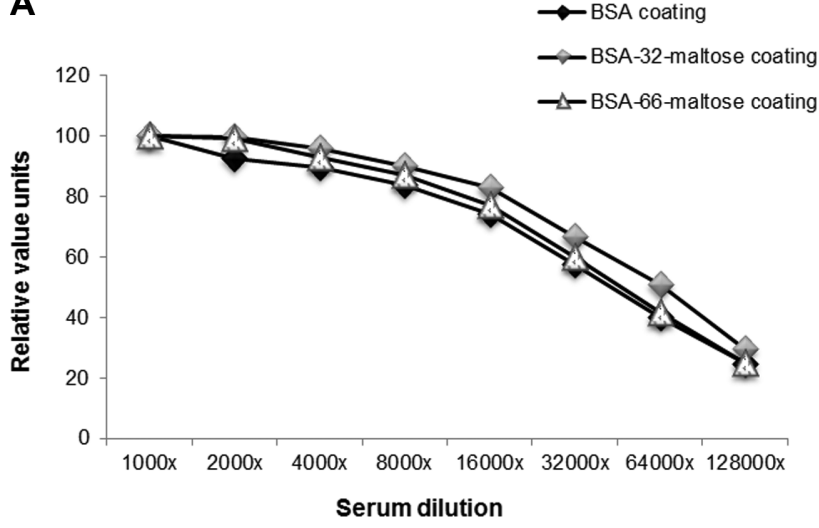

C

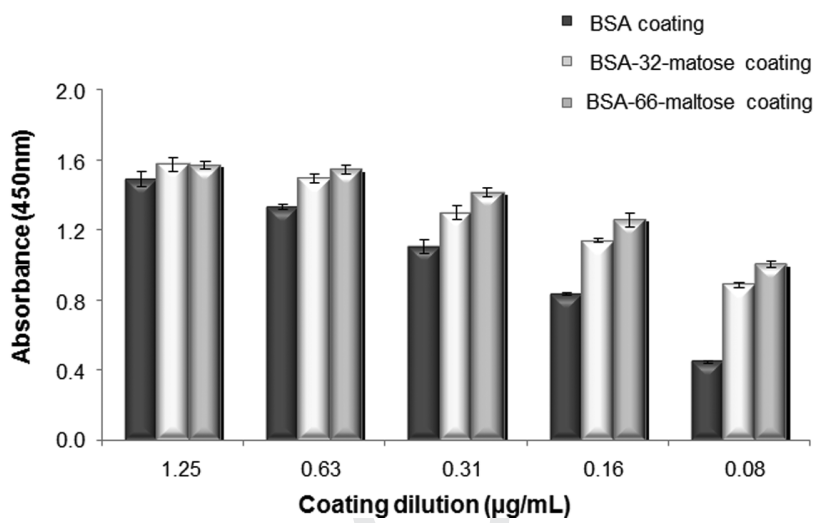

B

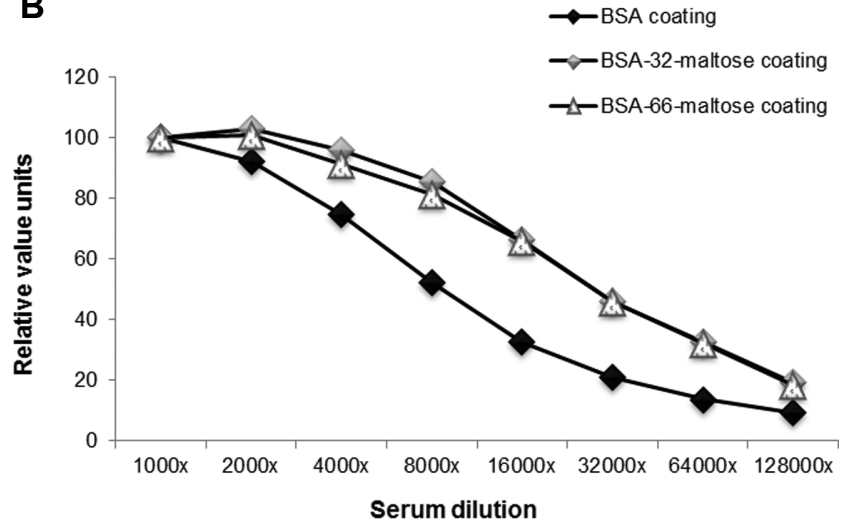

D

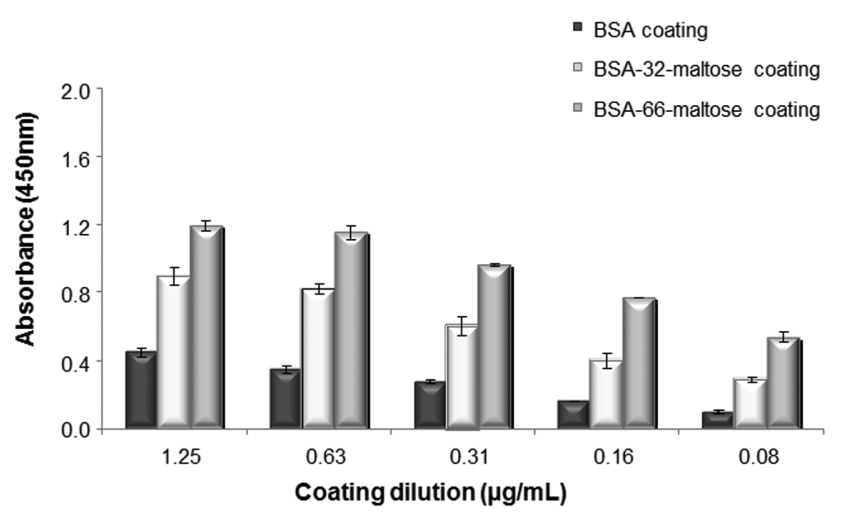

Figure 2. Polyclonal antibody response against the protein carrier and the synthesized neoglycoproteins. Antiglycan antibodies produced by immunization with BSA-32-maltose (Panels $A$ and $C$ ) and BSA-66-maltose (Panels B and D) incorporated sugar-containing neoglycoproteins detected by ELISA. Experiments were done either by using a fixed amount of immobilized antigens $(10 \mu \mathrm{g} / \mathrm{mL})$; and serial (1000-128 $000 \times$ ) dilutions of immune-sera (Panels A and B), or by using serial dilution of immobilized antigens (from 1.25 to $0.08 \mu \mathrm{g} / \mathrm{mL}$ ) and 4000 -fold dilution of the sera.

BALC/c mice were immunized and the polyclonal antibody response, specific for the carrier molecule and the sugar component of the immunogen, was analyzed by ELISA. In mice, immunized with the BSA-32-maltose, a rather unified response was observed toward the different immunogens, as shown Fig. 2, panel A. In mice, immunized with the BSA66-maltose, the IgG response was more intense toward the modified immunogens and was distinguishable from that of the significantly weaker carrier-specific response as shown Fig. 2, panel B. This difference was even more pronounced 
A

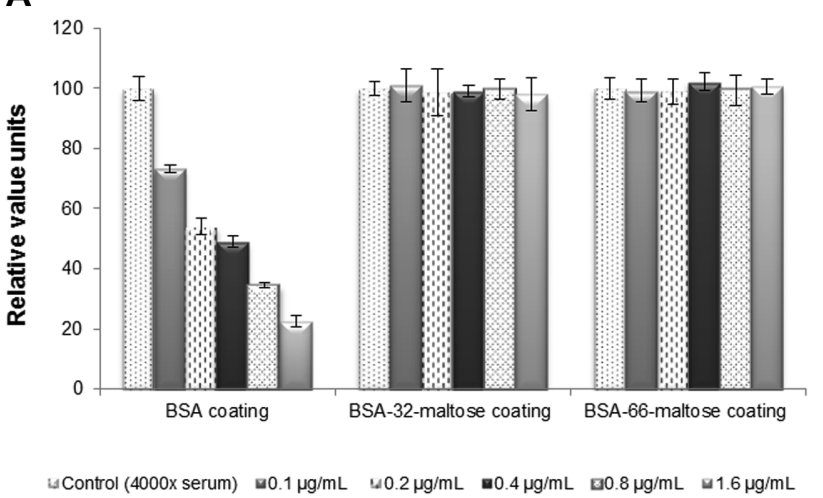

B 120

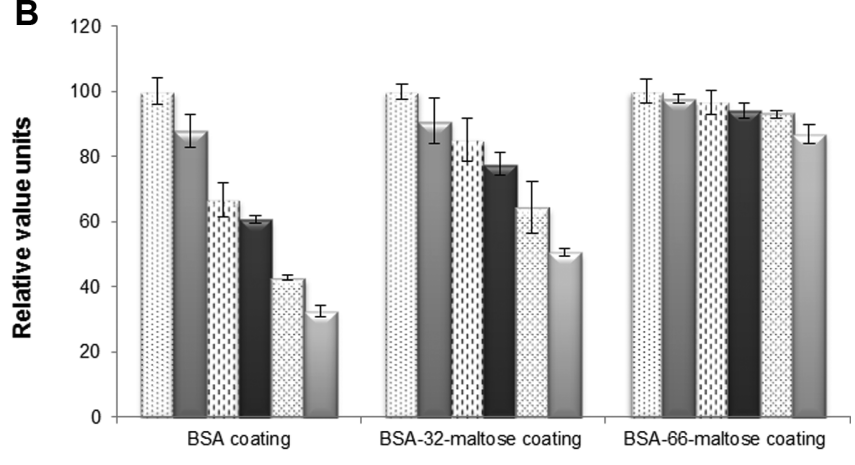

$\Delta$ Control (4000x serum) $\quad \square 0.1 \mathrm{ug} / \mathrm{mL} \quad \omega 0.2 \mathrm{ug} / \mathrm{mL} \quad \square 0.4 \mathrm{ug} / \mathrm{mL} \quad \square 0.8 \mathrm{ug} / \mathrm{mL} \quad \square 1.6 \mathrm{ug} / \mathrm{mL}$

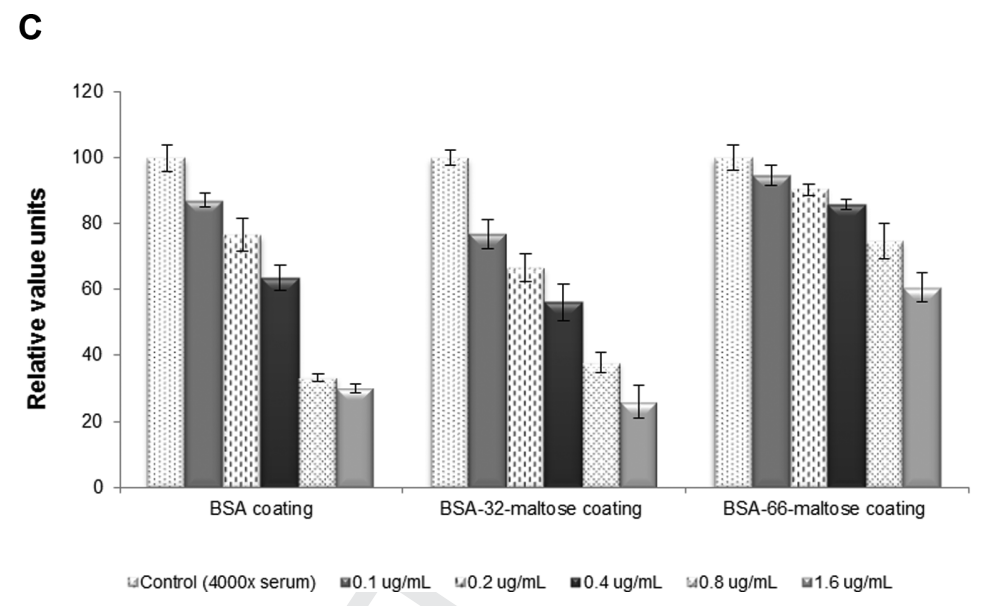

Figure 3. Specificity of the antiglycan antibody response. Inhibition studies of antiglycan antibody binding to their antigens using BSA (Panel A), BSA-32-maltose (Panel B), and BSA-66-maltose (Panel C) sugar incorporated glycoproteins as inhibitors. Antibodies (4000x serum dilutions, immunized with high sugar incorporated antigens in mice) were examined with all three coatings $(0.2 \mu \mathrm{g} / \mathrm{mL})$ in the presence of BSA inhibitor (0.1-1.6 $\mu \mathrm{g} / \mathrm{mL})$; BSA-32-maltose and BSA-66-maltose neoglycoprotein inhibitors $(0.1-1.6 \mu \mathrm{g} / \mathrm{mL})$.

when the experiment was conducted under immunogen limiting conditions. Panels $\mathrm{C}$ and $\mathrm{D}$ reveal that in the presence of limited amount of immunogen, a more significant antibody response could be observed against neoglycoproteins than against the carrier proteins, although the difference might vary depending on the immunogen used for immunization or even on the response of the individual animal. However, our results suggested that antibody populations specific for the neoglycoproteins were present in the mouse immune sera.

\subsection{Inhibition of mouse antibody binding to neoglycoproteins}

Inhibition experiments (ELISA) were performed in order to test the specificity of the polyclonal antibody response to the synthetic neoglycoproteins. The polyclonal antisera were reacted with immobilized BSA-32-maltose and BSA-66-maltose in the presence of inhibitors and Fig. 3 shows the results. Response to each immunogen, namely BSA, BSA-32-maltose, and BSA-66-maltose, was specifically inhibited by the corresponding immunogens, i.e. BSA-specific response was inhibited by BSA (Panel A), BSA-32-maltose-specific response was inhibited by BSA-32-maltose (Panel B), and BSA-66-maltosespecific response was inhibited by BSA-66-maltose (Panel C). In addition, BSA-32-maltose inhibited BSA-specific response (Panel B), while BSA-66-maltose inhibited both BSA- and BSA-32-specific responses (Panel C). However, none of the reactions could be inhibited by free maltose and other sugars such as glucose, isomaltose, lactose, galactose, and maltodextrin (data not shown), suggesting that the synthesized neoglycoproteins contained specific epitopes that were unique to the presence of the defined number of conjugated maltose units per BSA molecules. The results suggest that immunogenic neoepitopes were induced by maltose conjugation and increase in the maltose units from 32-maltose/BSA to 66-maltose/BSA resulted in the appearance of new epitopes not present on the BSA-32-maltose molecules. It remains to be determined, however, whether the new immunogenic epitopes included the sugar component or merely represented conformational changes of the core polypeptide chain 
induced by the sugar conjugation process. Nevertheless, it is anticipated that clonal analysis of the polyclonal response would identify mABs that recognize new sugar hapten specific epitopes where the synthetic sugar residue is a key component with respect to neoglycoprotein-specific IgG binding.

\section{Conclusions}

In this paper, we have demonstrated that custom synthesized neoglycoproteins could be utilized as immunogens to generate polyclonal antibodies against the neoepitopes. Surprisingly, the majority of epitopes detectable by polyclonal mouse antisera on native BSA were preserved by the conjugation process and/or by the attachment of eligomeric maltose molecules. In addition, specific antigenic epitopes were induced by conjugation of 32 maltose molecules and also by 66 maltose molecules, but the polyclonal antibody response to these neoepitopes was not inhibitable by maltose (or other simple or oligomeric sugars like glucose, isomaltose, lactose, galactose, and maltodextrin). The preliminary studies reported here enable to formulate a hypothesis and construct model systems that will allow further exploration of glycosylation-induced changes in protein structure and function. We propose that (i) glycosylation may not influence the majority of the antigenic epitopes, thus the overall structure of proteins may remain intact; (ii) glycosylation induces antigenic epitopes that are apparently independent of the native epitopes; (iii) in the majority of antibody responses to glycoproteins, key complementarity determining component of the immunogen may not be the sugar. Please note that we found no report in the literature suggesting that the core protein structure was changed by glycosylation changes. On the other hand, as disease-specific glycosylation changes have been widely reported, it would be desirable to obtain specific reagents that detect epitopes, which include the sugar moiety. Based on our current, and previous results, we suggest that it may be possible to obtain strictly maltose-specific mAbs by generating sufficiently large monoclonal antibody libraries via $\mathrm{mAb}$ proteomics [35]. However, as only few strictly sugarspecific $m A b s$ have been reported in the literature [36,37], we feel that the likelihood of obtaining such reagents is relatively low. We have to add that through extensive search in the literature, we were not able to find polyclonal antibody response to neoglycans with detectable specificity directed strictly to the sugar moiety.

The question still remains to be answered whether the structures of interest, in this particular study against maltose, play a critical role in inducing novel epitopes. For this purpose, the antibody response should be analyzed at the clonal level. Thus, based on our encouraging preliminary results, we plan to continue this work by conjugating complex diseasespecific sugar haptens to carriers with the goal to generate monoclonal antibody libraries for the discovery of mAbs in normal and disease models, with unique sugar specificities that can be readily applied to biomedical research and clinical diagnostics with the possible utilization of this approach to generate printed carbohydrate antibody microarrays.

This research was supported by the OTKA K-81839 and OTKA PD-73064 grant of the Hungarian Government, the Momentum LP2012042/2012 program of the Hungarian Academy of Sciences, and TAMOP 4.2.2.A-11/1/KONV-20120023 "VÉD-ELEM" grant. The technical assistance of Orosz Tóth Kata is greatly appreciated.

The authors have declared no conflict of interest.

\section{References}

[1] Dotan, N., Altstock, R. T., Schwarz, M., Dukler, A., Lupus 2006, 15, 442-450.

[2] Varki, A., Cummings, R. D., Esko, J. D., Freeze, H. H., Stanley, P., Bertozzi, C. R., Hart, G. W., Etzler, M. E. (Eds.), Essentials of Glycobiology, Cold Spring Harbor Laboratory Press, Cold Spring Harbor, NY 2009.

[3] Taylor, A. D., Hancock, W. S., Hincapie. M. Taniguchi, N., Hanash, S. M., Genome Med. 2009,

[4] Dotan, I., Fishman, S., Dgani, Y., Schwartz, M., Karban, A., Lerner, A., Weishauss, O., Spector, L., Shtevi, A., Altstock, R. T., Dotan, N., Halpern, Z., Gastroenterology 2006, 131, 366-378.

[5] de Boer, A. R., Hokke, C. H., Deelder, A. M., Wuhrer, M., Glycoconjugate J. 2008, 25, 75-84.

[6] Wang, C. C., Huang, Y. L., Ren, C. T., Lin, C. W., Hung, J. T., Yu, J. C., Yu, A. L., Wu, C. Y., Wong, C. H., Proc. Natl. Acad. Sci. USA 2008, 105, 11661-11666.

[7] Brettschneider, J., Jaskowski, T. D., Tumani, H., Abdul, S., Husebye, D., Seraj, H., Hill, H. R., Fire, E., Spector, L., Yarden, J., Dotan, N., Rose, J. W., J. Neuroimmunol. 2009, 217, 95-101.

[8] Heimburg-Molinaro, J., Rittenhouse-Olson, K., Methods Mol. Biol. 2009, 534, 341-357.

[9] Pazur, J. H., Adv. Carbohydr. Chem. Biochem. 1998, 53, 201-261.

[10] Monsigny, M., Roche, A.-C., Duverger, É., Srinivas, O., Carbohydrate-mediated Interactions. 3.23. Neoglycoproteins. Comprehensive Glycoscience. From Chemistry to Systems Biology, Elsevier, Amsterdam 2007.

[11] Avery, O. T., Goebel, W. F., J. Exp. Med. 1931, 54, 437-447.

[12] Legendre, H., Decaestecker, C., Goris Gbenou, M., Nagy, N., Hendlisz, A., Andre, S., Pector, J. C., Kiss, R., Gabius, H. J., Int. J. Oncol. 2004, 25, 269-276.

[13] Helling, F., Shang, A., Calves, M., Zhang, S., Ren, S., Yu, R. K., Oettgen, H. F., Livingston, P. O., Cancer Res. 1994, 54, 197-203.

[14] Lutz, H. U., Binder, C. J., Kaveri, S., Trends Immunol. 2009, 30, 43-51.

[15] Hakomori, S., Proc. Natl. Acad. Sci. USA 2002, 99, 10231-10233.

[16] Fuster, M. M., Esko, J. D., Nat. Rev. Cancer 2005, 5, 526-542.

[17] Jacob, F., Goldstein, D. R., Bovin, N. V., Pochechueva, T., Spengler, M., Caduff, R., Fink, D., Vuskovic, M. I., Huflejt, 
M. E., Heinzelmann-Schwarz, V., Int. J. Cancer 2012, 130, 138-146.

[18] Gray, G. R., Arch. Biochem. Biophys. 1974, 163, 426-428.

[19] Astronomo, R. D., Burton, D. R., Nat. Rev. Drug Discovery 2010, 9, 308-324.

[20] Buchs, J. P., Nydegger, U. E., J. Immunol. Methods 1989, 118, 37-46.

[21] Obukhova, P., Rieben, R., Bovin, N., Xenotransplantation 2007, 14, 627-635.

[22] Blixt, O., Head, S., Mondala, T., Scanlan, C., Huflejt, M. E., Alvarez, R., Bryan, M. C., Fazio, F., Calarese, D., Stevens, J., Razi, N., Stevens, D. J., Skehel, J. J., van Die, I., Burton, D. R., Wilson, I. A., Cummings, R., Bovin, N., Wong, C. H., Paulson, J. C., Proc. Natl. Acad. Sci. USA 2004, 101, 17033-17038.

[23] Huflejt, M. E., Vuskovic, M., Vasiliu, D., Xu, H., Obukhova, P., Shilova, N., Tuzikov, A., Galanina, O., Arun, B., Lu, K., Bovin, N., Mol. Immunol. 2009, 46, 3037-3049.

[24] Pochechueva, T., Jacob, F., Goldstein, D. R., Huflejt, M. E., Chinarev, A., Caduff, R., Fink, D., Hacker, N., Bovin, N. V., Heinzelmann-Schwarz, V., Glycoconjugate J. 2011, 28, 507-517.

[25] Cohen, A. S., Terabe, S., Smith, J. A., Karger, B. L., Anal. Chem. 1987, 59, 1021-1027.

[26] Ganzler, K., Greve, K. S., Cohen, A. S., Karger, B. L., Guttman, A., Cooke, N. C., Anal. Chem. 1992, 64, 2665-2671.
[27] Guttman, A., Electrophoresis 1995, 16, 611-616.

[28] Gomis, D. B., Junco, S., Exposito, Y., Gutierrez, M. D., Electrophoresis 2003, 24, 1391-1396.

[29] Szekrenyes, A., Roth, U., Kerekgyarto, M., Szekely, A., Kurucz, I., Kowalewski, K., Guttman, A., Anal. Bioanal. Chem. 2012, 404, 1485-1494.

[30] Zaia, J., Mass Spectrom. Rev. 2004, 23, 161-227.

[31] Hsu, N. Y., Yang, W. B., Wong, C. H., Lee, Y. C., Lee, R. T., Wang, Y. S., Chen, C. H., Rapid Commun. Mass Spectrom: RCM 2007, 21, 2137-2146.

[32] Clausen, M., Madsen, R., Carbohydr. Res. 2004, 339, 2159-2169.

[33] Lemieux, R. U., Bundle, D. R., Baker, D. A., J. Am. Chem. Soc. 1975, 97, 4076-4083.

[34] Schwartz, B. A., Gray, G. R., Arch. Biochem. Biophys. $1977,181,542-549$.

[35] Guergova-Kuras, M., Kurucz, I., Hempel, W., Tardieu, N., Kadas, J., Malderez-Bloes, C., Jullien, A., Kieffer, Y., Hincapie, M., Guttman, A., Csanky, E., Dezso, B., Karger, B. L., Takacs, L., Mol. Cell Proteomics 2011, 10, 1111 $010298 \mathrm{~A}$

[36] Nomoto, S., Muramatsu, H., Ozawa, M., Suganuma, T., Tashiro, M., Muramatsu, T., Exp. Cell. Res. 1986, 164, 49-62.

[37] Villarroya, S., Merand, B., Scholler, R., Pathol. Biol. (Paris) 1987, 35, 1155-1159. 